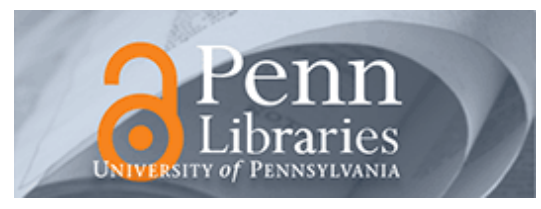

University of Pennsylvania

ScholarlyCommons

6-2014

\title{
Loopholes Undermine Donation: An Experiment Motivated by an Organ Donation Priority Loophole in Israel
}

Judd B. Kessler

Alvin E. Roth

Follow this and additional works at: https://repository.upenn.edu/bepp_papers

Part of the Public Economics Commons

\section{Recommended Citation}

Kessler, J. B., \& Roth, A. E. (2014). Loopholes Undermine Donation: An Experiment Motivated by an Organ Donation Priority Loophole in Israel. Journal of Public Economics, 114 (C), 19-28. http://dx.doi.org/ 10.1016/j.jpubeco.2013.12.006

This paper is posted at ScholarlyCommons. https://repository.upenn.edu/bepp_papers/130

For more information, please contact repository@pobox.upenn.edu. 


\title{
Loopholes Undermine Donation: An Experiment Motivated by an Organ Donation Priority Loophole in Israel
}

\begin{abstract}
Giving registered organ donors priority on organ waiting lists, as has been implemented in Israel and Singapore, provides an incentive for registration and has the potential to increase the pool of deceased donor organs. However, the implementation of a priority rule might allow for loopholes - as is the case in Israel - in which an individual can register to receive priority but avoid ever being in a position to donate organs. We experimentally investigate how such a loophole affects donation and find that the majority of subjects use the loophole when available. The existence of a loophole completely eliminates the increase in donation generated by the priority rule. When information about loophole use is made public, subjects respond to others' use of the loophole by withholding donation such that the priority system with a loophole generates fewer donations than an allocation system without priority.
\end{abstract}

\section{Keywords}

organ donation, experiments, public goods

\section{Disciplines}

Public Economics 


\title{
Loopholes Undermine Donation: An Experiment Motivated by an Organ Donation Priority Loophole in Israel*
}

\author{
By Judd B. Kessler ${ }^{\dagger}$ and Alvin E. Roth
}

This Draft: November 9, 2013

\begin{abstract}
Giving registered organ donors priority on organ waiting lists, as has been implemented in Israel and Singapore, provides an incentive for registration and has the potential to increase the pool of deceased donor organs. However, the implementation of a priority rule might allow for loopholes - as is the case in Israel - in which an individual can register to receive priority but avoid ever being in a position to donate organs. We experimentally investigate how such a loophole affects donation and find that the majority of subjects use the loophole when available. The existence of a loophole completely eliminates the increase in donation generated by the priority rule. When information about loophole use is made public, subjects respond to others' use of the loophole by withholding donation such that the priority system with a loophole generates fewer donations than an allocation system without priority.
\end{abstract}

Keywords: Organ Donation; Experiments; Public Goods

- The authors thank the staff at the Wharton Behavioral Lab at the University of Pennsylvania. Both authors materially participated in the research and article preparation, and the authors have no conflict of interests related to this paper.

${ }^{\dagger}$ Department of Business Economics and Public Policy, The Wharton School, University of Pennsylvania, 3620 Locust Walk, Philadelphia, PA 19104; (215) 898-7696;

judd.kessler@wharton.upenn.edu (corresponding author)

ॠDepartment of Economics, Stanford University, Stanford, CA 94305; alroth@stanford.edu 


\section{Introduction}

There are currently over 120,000 people in the United States waiting for a lifesaving organ transplant, the majority of which come from deceased donors. ${ }^{1}$ But even though one deceased donor can save numerous lives and registering to be an organ donor is relatively easy (e.g. checking a box on a form at the state department of motor vehicles), only 43\% of eligible Americans have registered (Donate Life America 2012).

Understanding what motivates individuals to register as organ donors - and, more generally, what motivates individuals to privately provide public goods - is essential to model behavior and to implement successful policy. ${ }^{2}$ In introducing the concept of warm glow (Andreoni 1988, 1989, 1990), Jim Andreoni made the discipline recognize that forces beyond pure altruism (Becker 1974) influence public good provision. It is a tribute to Jim, to whom this special issue is dedicated, that we can think clearly about these forces and that we have a rich vocabulary to talk about the various motivations at play in the private provision of public goods.

As in most complicated environments, many of these motivations are at play when an individual makes the decision to register as an organ donor. A deceased donor has the potential to save numerous lives, generating an altruistic motive for registration. Since deceased donation benefits others, individuals might get warm glow from the act of registering. Finally, individuals might be reciprocal and be motivated to register when others register as well. Even when taken together, however, these motivations have not generated enough deceased donations to halt the steady lengthening of organ transplant waiting lists. For example, the kidney waiting list has grown continuously over the past decade (see Table 1$){ }^{3}$

\footnotetext{
${ }^{1}$ In 2012, nearly $80 \%$ of transplanted organs came from deceased donors (based on OPTN data accessed Nov. 9, 2013, http://optn.transplant.hrsa.gov/). Deceased donors agree to make their organs available upon death and can provide multiple vital organs (i.e. kidneys, liver, heart, pancreas, lungs, and intestine) and other tissues (e.g. corneas, skin, heart valves, cartilage, bone, tendons, and ligaments) whereas living donors overwhelmingly donate one kidney.

${ }^{2}$ This is particularly true in the context of organ donation, for which federal legislation prohibits the use of monetary incentives (see Roth 1997).

${ }^{3}$ The kidney waiting list currently stands above 98,500, based on OPTN data accessed Nov. 9, 2013 (http://optn.transplant.hrsa.gov/latestData/rptData.asp). The long waiting list for kidneys results in part from the ability for kidney dialysis to keep patients with kidney failure alive for
} 
Table 1: U.S. Kidney Donors, Transplants, and Waiting List

\begin{tabular}{|c|c|c|c|c|c|}
\hline & $\begin{array}{c}\text { Deceased } \\
\text { Donors }\end{array}$ & $\begin{array}{c}\text { Deceased } \\
\text { Donor } \\
\text { Transplants }\end{array}$ & $\begin{array}{c}\text { Living } \\
\text { Donors }\end{array}$ & $\begin{array}{c}\text { All Wait } \\
\text { List Patients }\end{array}$ & $\begin{array}{c}\text { New Wait } \\
\text { List } \\
\text { Additions }\end{array}$ \\
\hline 2002 & 5,638 & 8,539 & 6,241 & 50,301 & 23,630 \\
\hline 2003 & 5,753 & 8,668 & 6,473 & 53,530 & 24,680 \\
\hline 2004 & 6,325 & 9,359 & 6,647 & 57,168 & 27,278 \\
\hline 2005 & 6,700 & 9,913 & 6,573 & 61,562 & 29,140 \\
\hline 2006 & 7,176 & 10,660 & 6,436 & 66,352 & 32,356 \\
\hline 2007 & 7,240 & 10,591 & 6,043 & 71,862 & 32,416 \\
\hline 2008 & 7,188 & 10,553 & 5,968 & 76,089 & 32,577 \\
\hline 2009 & 7,248 & 10,442 & 6,387 & 79,397 & 33,652 \\
\hline 2010 & 7,241 & 10,622 & 6,278 & 83,919 & 34,404 \\
\hline 2011 & 7,434 & 11,043 & 5,771 & 86,547 & 33,564 \\
\hline 2012 & 7,421 & 10,868 & 5,620 & 89,576 & 34,834 \\
\hline
\end{tabular}

The data is provided by OPTN as of Nov. 1, 2013. New Wait-list Additions counts patients (rather than registrants) to eliminate the problems of counting multiple times people who register in multiple centers. All Wait-list Patients also counts patients rather than registrants. All Wait-list Patients data through 2011 is from the 2008, 2009, and 2011 OPTN/SRTR Annual Reports, 2012 is calculated using 2011 data and 2012 New Wait List Additions and Wait List Removals data.

Since private provision has failed to generate enough deceased donor organs, policy makers are looking for other ways to motivate individuals to register as donors. While U.S. law prevents monetary incentives for organ donation, there are other ways to incent registration, one of which is to provide priority on organ donor waiting lists to those who previously registered as donors. Under the current U.S. organ allocation system, which is similar to the systems in most other nations, priority on waiting lists is given to those who have been waiting the longest or those with the most immediate medical need. ${ }^{4}$ Under a priority system, organ allocation would also depend on whether an individual previously registered as organ donor, with registered donors getting an organ more quickly than those who are not registered. This policy has been studied experimentally (Kessler and Roth 2012) and has been implemented in Singapore and, most recently, in Israel. In Israel, the policy appears to have increased the number of

many years. No dialysis exists for other organs. Waiting lists for other organs are shorter in part because many patients on those lists die while waiting.

${ }^{4}$ The allocation rules vary by organ. In the United States, kidney allocation is primarily by waiting time while liver allocation is primarily by medical need. These policies are a function of feasible medical care: while kidney dialysis allows patients to survive for years without a kidney transplant, a patient whose liver fails will die very quickly without a liver transplant. 
deceased donor organs and the organ donor registration rate, at least temporarily (Lavee et al. 2013), although the research into its effectiveness is ongoing.

One concern with implementing priority for registered donors is the possibility that loopholes in the system would allow individuals to register and receive priority but avoid ever being in a position to donate their organs. For example, an organ allocation system could be gamed is if it allowed individuals to receive priority immediately upon registration, letting individuals wait until they needed an organ to register as a donor effectively giving them priority without requiring anything in return. Careful implementation of allocation rules can eliminate this scope for gaming. In Israel, individuals who did not register by April 1, 2012 only get priority three years after they join the registry.

While the Israeli legislation mitigated this particular type of gaming, it introduced a different loophole in the organ allocation system. One of the reported motivations for implementing the priority allocation legislation in Israel was widespread concern over free riding by ultraorthodox religious groups. These groups generally do not recognize brain death (i.e. when the brain ceases to function) as a valid form of death and consequently oppose providing deceased donor organs. ${ }^{5}$ Members of these religious groups do not oppose receiving organs, however, even those recovered from brain dead donors. It has been argued that this group of explicit free riders - those who will accept organs but not provide them - is a major factor for the historically low rates of organ donation in Israel (Lavee et al. 2010, Lavee and Brock 2012). The priority allocation system was meant to minimize this free riding by rewarding registered donors and giving free riders lower priority on waiting lists.

Nevertheless, the implementation of the Israeli priority legislation created a loophole that may allow this type of free riding to continue. The Israeli donor card gives a registrant the option to check a box requesting that a clergyman be consulted before

\footnotetext{
${ }^{5}$ Most organ donation follows brain death, since the deceased patient can be left on a respirator, allowing the organs to be kept alive until they are recovered. Cardiac death (when there is an irreversible loss of circulation) requires fast action, on the order of a few minutes, for organ recovery to be possible. Data from the New England Organ Bank (NEOB) indicates that in New England recovery rates are much higher among potential donors who died from brain death than cardiac death. Recovery rates were about 20 percentage points higher for registered donors and about 15 percentage points higher for non-registered donors in 2010, 2011, and 2012. (Personal communication, Sean Fitzpatrick, NEOB.)
} 
organ donation occurs (see Figure 1). ${ }^{6}$ An individual who wants priority but does not want to be a donor could check that box with the implicit or explicit understanding that his clergyman would refuse donation if the supposed "donor" were to die and be in a position to have his organs recovered.

Figure 1: Donor Card in Israel

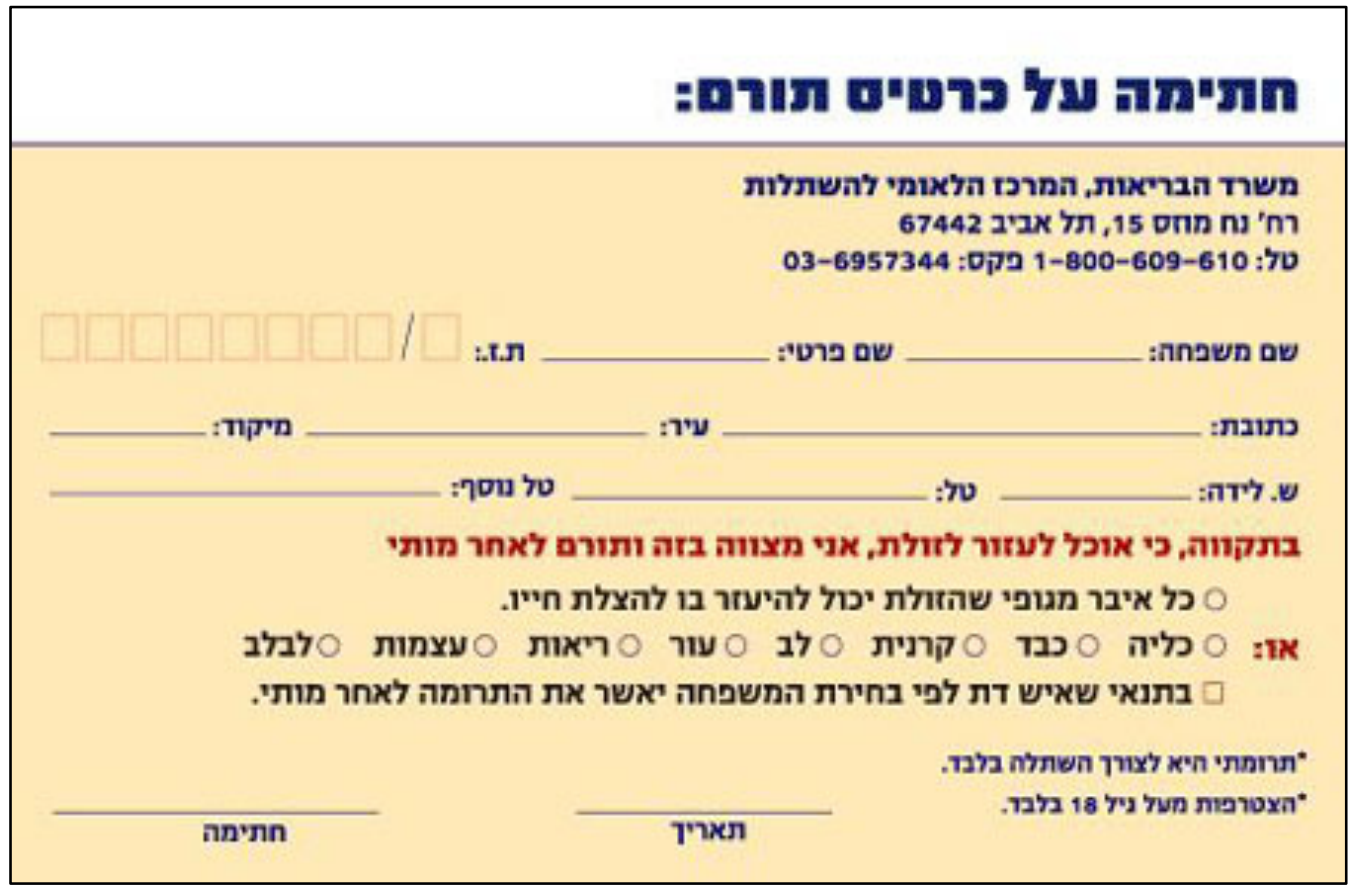

Translated into English the card (emphasis and color in original) reads:

With the hope that I may be of help to another, I hereby order and donate after my death:

() Any organ of my body that another my find of use to save his/her life.

Or: () Kidney () Liver () Cornea () Heart () Skin () Lungs () Bones () Pancreas

[] As long as a clergyman chosen by my family will approve the donation after my death.

Even without an explicit checkbox, there is still the potential for a loophole to be abused in the Israeli priority system. Signing the donor card in Israel is not binding, so next of kin are still asked about donation and can block the donation of a deceased who had signed a donor card (Lavee and Brock 2012). ${ }^{7}$ When next of kin make the final

\footnotetext{
${ }^{6}$ During implementation, a number of people specifically advocated for this clergyman checkbox option to remain on the card - amid suspicion that it was motivated by religious groups who wanted to receive priority without having to donate (see http://www.haaretz.com/printedition/news/officials-new-donor-cards-will-reduce-organ-transplants-1.374566).

${ }^{7}$ This is also the case in the United States, where next of kin can refuse donation even if the deceased had previously joined a state registry (Glazier 2006).
} 
donation decision or can block the donation of a registered donor, individuals can register as donors to receive priority but instruct their next of kin to prevent their organs from being donated upon death, creating a loophole even if one is not explicitly available.

What is the potential effect of such a loophole on the efficacy of a priority allocation system? A loophole might eliminate the incentive to donate generated by the priority system, since individuals can register to get priority but take advantage of the loophole rather than donate. Additionally, however, the loophole might interact with individuals' prosocial motivations for providing the public good. In particular, the loophole introduces a very explicit form of free riding in which free riders not only fail to donate but also abuse a system designed to reward contributors. This abuse could "poison the pool" and lead individuals who would have donated in the absence of priority to decide against donation in response to others taking advantage of the loophole. If a loophole poisons the pool, then introducing a priority system with a loophole might backfire and lead to fewer donors than the system without priority.

In this study, we use a laboratory game modeled on the decision to register as an organ donor to investigate how the existence of a loophole in a priority allocation system affects behavior. It will be years before we have data on actual donations and actual loophole use in Israel, but here we are able to study the loophole, understand what consequences it can have, and anticipate its effects. Certainly, some hypotheses about organ donation can only be investigated by asking for real organ donor registrations (see Kessler and Roth 2013). However, a number of important aspects about the organ donation decision and the organ allocation system cannot be easily manipulated in practice but can be manipulated and studied in the laboratory. We can use the laboratory to study the incentive issues involved in organ donation, abstracted away from the important but complex sentiments associated with actual organs. ${ }^{8}$

In this paper, we replicate previous results from Kessler and Roth (2012) and find that a priority allocation system generates significantly higher organ donation rates,

\footnotetext{
${ }^{8}$ In practice, the costs of registering as an organ donor are difficult to identify. Costs may include fears about differential medical care for registered organ donors, fears that organs will be removed at a time or in a manner that is inconsistent with religious beliefs, or simply discomfort from thinking about death. In the laboratory, we can (1) impose monetary costs to model (to some level of approximation) the costs faced by donors and (2) control those costs, for example by giving some potential donors low costs and others high costs.
} 
increasing the number of organs recovered and overall efficiency. ${ }^{9}$ In addition, we find that providing a loophole that allows non-donors to get priority completely eliminates the incentive from priority. When a loophole is available, almost all non-donors take the loophole so that $96 \%$ of subjects have priority.

We also find evidence that providing a loophole can poison the pool, inducing individuals who would have donated in the absence of a priority system to withhold donation when a loophole is available. This decrease in giving occurs primarily when individuals have information about how many people took advantage of the loophole. Investigating the dynamics of donation suggests that individuals withhold donation when they observe others take the loophole. Observing others take the loophole decreases donation even controlling for the number of individuals who donate, demonstrating that individuals respond to others taking the loophole both because those individuals are not donating and because they are choosing to take priority through the loophole rather than remaining in the non-donor priority class.

The results of this study enter a rich literature on motivations for private provision of public goods. A closely related literature that is also in the medical donation domain focuses on blood donation and primarily investigates whether incentives for donation can cause a "crowding out" that might lead to less donation overall. This work has generally found that incentives increase donations without leading to a decrease in blood quality (see Mellstrom and Johannesson 2008; Lacetera and Macis 2010a,b; Lacetera, Macis and Slonim 2012) ${ }^{10}$ In our experiment, we also find that an incentive - in the form of priority - increases donation rates. In addition we find that decisions are influenced by the choices of other subjects to donate or to take the loophole, particularly when those choices are observable. This finding relates to a vast literature on social information and conditional cooperation in public goods games in which subjects have been shown to conform to the public good contributions of others (for laboratory results, see Keser and van Winden 2000; Fischbacher, Gachter and Fehr 2001; and Potters, Sefton and

\footnotetext{
${ }^{9}$ The experimental parameters in this study are quite different from our earlier work, but the same pattern emerges.

${ }^{10}$ For evidence of crowding out in other contexts, see Titmuss (1970); Deci, Koestner and Ryan (1999); Gneezy and Rustichini (2000a,b); and Ariely, Bracha and Meier (2009). For theory see Benabou and Tirole (2006).
} 
Vesterlund 2005; for field results in the context of charitable giving, see Frey and Meier 2004 and Shang and Croson 2009).

\section{Experimental Design}

Subjects played a game modeled on the decision to register as an organ donor. In the experiment, registering as a donor led automatically to donation when possible and so we refer to registering in the experiment as "donating". In the instructions to subjects, the experiment was described in abstract terms rather than in terms of organs. Subjects started each round with one "A unit" (representing a brain) and two "B units" (representing two kidneys). ${ }^{11}$

Each round of the game, subjects were endowed with $\$ 6$, an A unit, and two B units, and each subject received one of two health outcomes. Each subject either had Bunit failure, in which case both B units failed and the subject needed a B unit to earn more money in the round, or had A-unit failure, in which case he did not earn any more money in the round. Each round, before observing his health outcome, each subject decided whether to pay a cost of donation that would make his B units available to others if he had A-unit failure. Subjects were randomly assigned the cost of donation (either $\$ 0.50$ or $\$ 4.00$, constant for a subject during the entire study) that they had to pay if they registered as a donor. ${ }^{12}$

If a subject paid the cost of donation in a round and had A-unit failure in that round, then each of his B units were given to a subject with B-unit failure. ${ }^{13}$ Subjects played in a fixed group of 8 players and were told that 2 of the 8 subjects would be randomly selected to have A-unit failure in each round (and thus the probability of A-unit

\footnotetext{
${ }^{11}$ The design here is similar to the game in Kessler and Roth (2012) but with different parameters and a simpler, two-stage implementation. In the results section, we first confirm that we replicate the pattern of findings from Kessler and Roth (2012) that a priority allocation rule generates more donors and then present our new results investigating the loophole.

${ }^{12}$ Note that we are modeling the cost of organ donation as a cost of registering to be a donor rather than of having the organs recovered (i.e. removed). Deceased donation occurs after death, when we generally assume that utility flows stop and an individual no longer incurs costs or benefits.

${ }^{13}$ As noted above, subjects were always asked for their donation decision before they learned their health outcome. That is, they had to decide whether to pay the cost of donation before they knew whether they would have A-unit failure (in which case their B-units could be given to other subjects) or B-unit failure (in which case their B-units would be useless).
} 
failure was 25\%) and that the other 6 would have B-unit failure (and thus the probability of B-unit failure was $75 \%$ ). In each round, 0,2 , or $4 \mathrm{~B}$ units were made available depending on whether neither, one, or both subjects who ended up with A-unit failure paid the cost to register as a donor. Consequently, either 0,2 , or 4 of the six players with B-unit failure received a B unit in each round.

Subjects with B-unit failure who received a B unit earned an additional $\$ 4.00$ in the round. Subjects with A-unit failure and subjects with B-unit failure who did not receive a $\mathrm{B}$ unit from another player did not earn any additional money in the round. ${ }^{14}$ Since there were always six subjects with B-unit failure, a subject who paid the cost of donation and had A-unit failure always provided B units to two other subjects. Those subjects each earned an additional $\$ 4.00$ from receiving the B unit. Consequently, paying the cost of donation generated $\$ 2.00$ in expectation for other subjects (i.e. with $25 \%$ probability paying the cost of donation generated a total of $\$ 8.00$ in extra earnings for other subjects).

The experimental design varied the organ allocation rules and the amount of information provided to subjects. There were three different allocation conditions and two different information conditions, generating six different treatments in a $3 \times 2$ design as shown in Table 2. We first describe the organ allocation conditions and then the information conditions.

Table 2: The 3x2 Experimental Design

\begin{tabular}{|c|c|c|c|c|}
\hline \multirow{2}{*}{\multicolumn{2}{|c|}{$\begin{array}{c}3 \times 2 \\
\text { Design }\end{array}$}} & \multicolumn{3}{|c|}{ Organ Allocation Condition } \\
\hline & & Control & Priority & Loophole \\
\hline \multirow{2}{*}{ 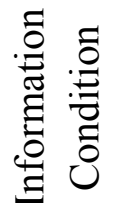 } & Low & Control, Low Info & Priority, Low Info & Loophole, Low Info \\
\hline & High & Control, High Info & Priority, High Info & Loophole, High Info \\
\hline
\end{tabular}

The organ allocation conditions differed in how B units were allocated to subjects with B-unit failure. In the control condition, any available B units were assigned

\footnotetext{
${ }^{14}$ These subjects had round earnings equal to their initial $\$ 6.00$ minus their cost of donation (if paid). Subjects who received a B unit earned that amount plus $\$ 4.00$.
} 
randomly to the subjects with B-unit failure; all subjects with B-unit failure were equally likely to receive a B unit. The control condition models the first-come-firstserved waiting list system in the United States (with subjects arriving onto the waiting list in a random order and a limited number of organs available). In each round of the control condition, the subject was reminded of his cost of donation and then asked to choose between two options: "Yes, I want to donate my B units" or "No, I do not want to donate my B units".

In the priority condition, subjects who had paid the cost of donation, but ended up needing a B unit, received priority for available B units. Subjects who paid the cost of donation and had B-unit failure were in a priority group, and any available B units were first assigned randomly among subjects in the priority group; all subjects in the priority group were equally likely to receive a B unit. Only if all subjects in the priority group had received a $B$ unit were any $B$ units distributed to subjects who had not paid the cost of donation. In this case, any remaining B units were randomly assigned to subjects with Bunit failure who did not pay the cost of donation; each of these subjects was equally likely to receive one of the remaining $B$ units. This is a very extreme form of priority in that no subject without priority ever received a B unit unless all subjects with priority had received one. In each round of the priority condition, the subject was reminded of his cost of donation and then asked to choose between two options: "Yes, I want to donate my B units and receive priority for a B unit if I need one" or "No, I do not want to donate my B units".

In the loophole condition, B units were assigned as in the priority condition, but subjects could join the priority group either by paying the cost of donation or by asking to receive priority without paying the cost. In each round of the loophole condition, the subject was reminded about his cost of donation and then asked to choose between three options, the two options listed in the priority condition above and "No, I do not want to donate my B units, but I do want to receive priority for a B unit if I need one". Throughout the paper, we refer to this last option as receiving priority by taking advantage of a loophole (or just "taking the loophole"). 
In addition to varying the organ allocation rule, the experiment also varied the information provided to subjects about the costs of donation and the decisions of other subjects in their group.

In the low information condition, subjects only knew their own cost of donation (but not the costs of donation of the other members of their group) and they knew for each round whether they had B-unit failure and, if so, whether they received a B unit (but not the number of donors or the number of people who took the loophole in that round). The low information condition was meant to provide noisy feedback with regard to the number of registered donors and the number of people taking advantage of the loophole: subjects could only infer this information from their own experience of receiving (or not receiving) a B unit when they needed one.

In the high information condition, subjects were also told the distribution of costs of donation of the other group members and (at the end of each round) how many group members paid the cost of donation, how many group members chose not to donate, and how many group members took advantage of the loophole (when it was available).

The amount of information provided to agents about the priority system is a choice variable of a policy maker, and we suspected it might impact how the loophole affected behavior. The low information setting is meant to model an environment in which policy makers are opaque about the number of individuals who register and donate. The high information setting is meant to model an environment in which policy makers provide more information about the number of people who register and who take advantage of the loophole when it is available.

Subjects stayed in the same information condition (either low information or high information) for the entire study but played in two different organ allocation conditions. Subjects were not told how many rounds of the game they would play, but after they played 15 rounds in one organ allocation condition they were informed that the rules of the game had changed. The rule changes were explained and then the group played 15 more rounds in a different organ allocation condition. Each session had 16 subjects who played in one of two fixed groups of 8 subjects, and both groups in a session played in the same order of organ allocation conditions so instructions could be read aloud. 
At the start of the session, subjects were told that one round from the study would be randomly selected for cash payment and that they would take home their earnings from that round. After all rounds had been played, subjects were informed of the round that had been randomly selected for cash payment and all subjects were paid their earnings from that round in cash along with a $\$ 10$ show-up fee.

A total of 608 subjects participated in one of 38 sessions run at the Wharton Behavioral Lab during the fall of 2012. Subjects were college students who participated for one hour and made decisions anonymously on computer terminals. Average earnings were $\$ 16.62$ per subject, including a $\$ 10$ show up fee. The experiment was conducted using z-Tree 3.2.8 (Fischbacher 2007).

Since subjects started in one of the three organ allocation conditions and then switched to one of the other two, there are six possible organ allocation condition orders. Table 3 shows the number of sessions, groups, and subjects who participated in each order of the conditions under low information and under high information.

Table 3: Number of Sessions, Groups, and Subjects in Each Condition Order

\begin{tabular}{|c|c|c|c|c|c|c|}
\hline & \multicolumn{6}{|c|}{ Organ Allocation Condition Order } \\
\hline & $\begin{array}{l}\text { Control, } \\
\text { Priority }\end{array}$ & $\begin{array}{c}\text { Control, } \\
\text { Loophole }\end{array}$ & $\begin{array}{l}\text { Priority, } \\
\text { Control }\end{array}$ & $\begin{array}{c}\text { Priority, } \\
\text { Loophole }\end{array}$ & $\begin{array}{c}\text { Loophole, } \\
\text { Control }\end{array}$ & $\begin{array}{c}\text { Loophole, } \\
\text { Priority }\end{array}$ \\
\hline $\begin{array}{c}\text { Low } \\
\text { Information }\end{array}$ & $\begin{array}{c}4 \text { sessions } \\
\text { (8 groups, } \\
64 \mathrm{Ss} \text { ) }\end{array}$ & $\begin{array}{c}4 \text { sessions } \\
\text { (8 groups, } \\
64 \mathrm{Ss})\end{array}$ & $\begin{array}{c}3 \text { sessions } \\
\text { (6 groups, } \\
48 \mathrm{Ss})\end{array}$ & $\begin{array}{c}3 \text { sessions } \\
\text { (6 groups, } \\
48 \mathrm{Ss})\end{array}$ & $\begin{array}{c}3 \text { sessions } \\
\text { (6 groups, } \\
48 \mathrm{Ss} \text { ) }\end{array}$ & $\begin{array}{c}3 \text { sessions } \\
\text { (6 groups, } \\
48 \mathrm{Ss} \text { ) }\end{array}$ \\
\hline $\begin{array}{c}\text { High } \\
\text { Information }\end{array}$ & $\begin{array}{c}4 \text { sessions } \\
\text { (8 groups, } \\
64 \mathrm{Ss} \text { ) }\end{array}$ & $\begin{array}{c}3 \text { sessions } \\
\text { (6 groups, } \\
48 \mathrm{Ss} \text { ) }\end{array}$ & $\begin{array}{c}4 \text { sessions } \\
\text { (8 groups, } \\
64 \mathrm{Ss} \text { ) }\end{array}$ & $\begin{array}{c}2 \text { sessions } \\
\text { (4 groups, } \\
32 \mathrm{Ss} \text { ) }\end{array}$ & $\begin{array}{c}2 \text { sessions } \\
\text { (4 groups, } \\
32 \mathrm{Ss} \text { ) }\end{array}$ & $\begin{array}{c}3 \text { sessions } \\
\text { (6 groups, } \\
48 \mathrm{Ss} \text { ) }\end{array}$ \\
\hline
\end{tabular}

\section{Experimental Results}

The main result of interest is whether subjects pay the cost of donation so that if they have A-unit failure their B units will be made available to others. Figure 2 displays, by round and condition, the percentage of subjects paying the cost of donation. The top panel, Panel A, displays the data from subjects playing in the low information conditions. The bottom panel, Panel B, displays the data from subjects playing in the high 
information conditions. Notice that in each panel, the data lines are broken after round 15. This gap indicates that different groups comprise the data in Rounds 1-15 and the data in Rounds 16-30 for each organ allocation condition.

While the incentives and parameters in this experiment differ from our previous work (Kessler and Roth 2012), Figure 2 demonstrates that we replicate the finding that providing priority for registered donors leads to significantly higher rates of donation. Combining data from the high and low information conditions, the donation rate across all subjects is $69.3 \%$ in the priority condition and $40.9 \%$ in the control condition This 28.4 percentage point difference represents a $70 \%$ increase in the donation rate.

Table 4 presents linear probability model estimates of donation. Across all specifications, the coefficient on Priority is positive and significant, indicating that the priority rule increases the probability of donation over the control condition. Regressions (1) through (4) analyze data from the first 15 rounds, when subjects have only played in one organ allocation condition. These provide a clean between-subject estimate of the effect of our organ allocation conditions on behavior, before subjects have experienced multiple organ allocation conditions. Regressions (5) through (8) analyze data from all 30 rounds together. Regressions (2) and (6) control for Info (indicating that data came from the high information conditions) and include interactions with Info. Regressions (3), (4), (7), and (8) look at effects in the low information condition or in the high information condition separately. 
Figure 2: Probability of Donation by Treatment and Round
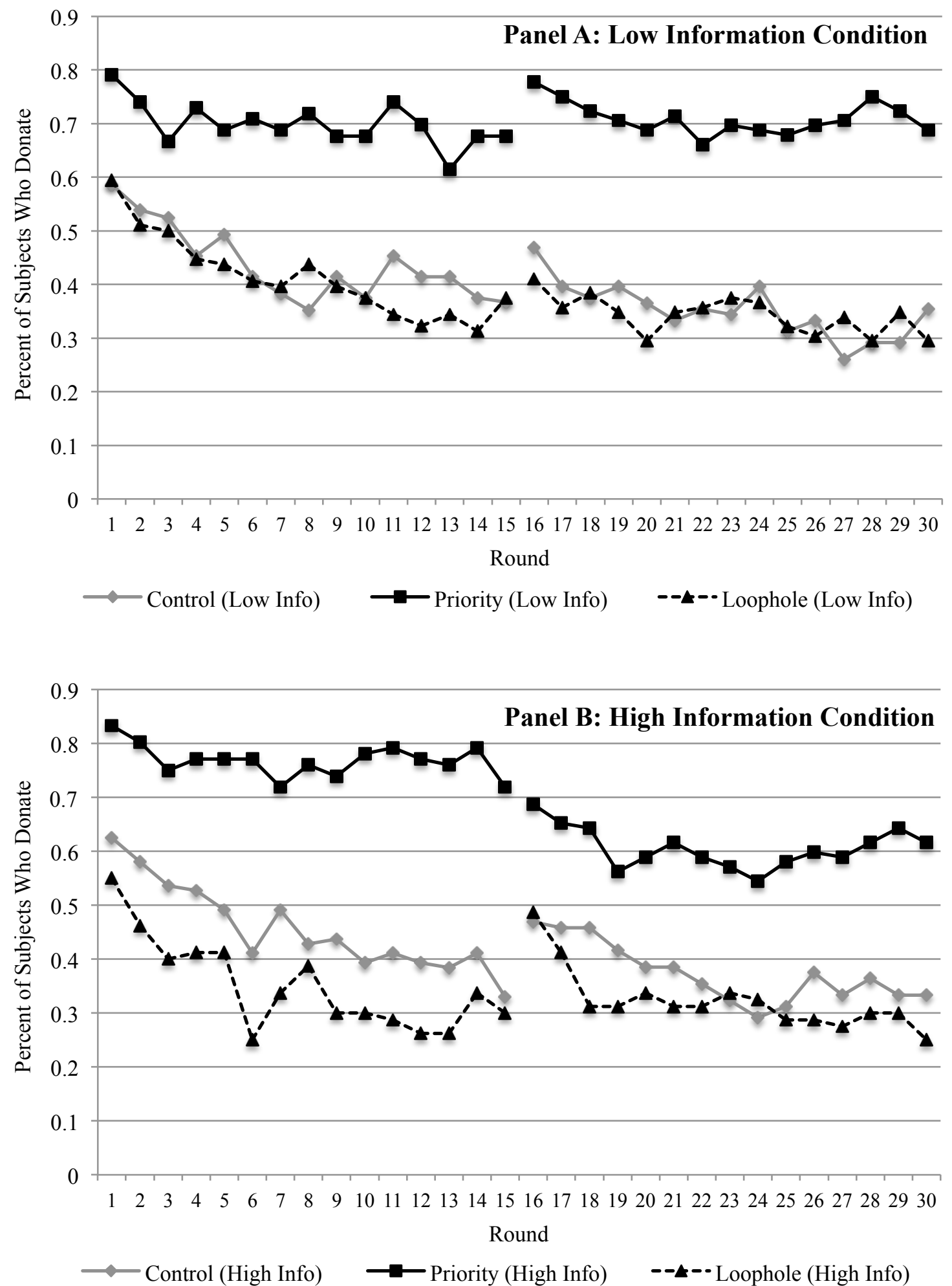

Lines are broken after round 15 to indicate that different groups comprise the data for Rounds 1-15 and for Rounds 16-30 
Table 4: Organ Registration By Condition

Donation ( 0 or 1$)$ in a Linear Probability Model (OLS)

\begin{tabular}{|c|c|c|c|c|c|c|c|c|}
\hline & \multicolumn{4}{|c|}{ First 15 Rounds } & \multicolumn{4}{|c|}{ All 30 Rounds } \\
\hline & \multicolumn{2}{|c|}{ All Data } & \multirow{2}{*}{$\begin{array}{c}\text { Low Info } \\
\text { Only } \\
(3)\end{array}$} & \multirow{2}{*}{$\begin{array}{l}\text { High Info } \\
\text { Only } \\
(4)\end{array}$} & \multicolumn{2}{|c|}{ All Data } & \multirow{2}{*}{$\begin{array}{c}\text { Low Info } \\
\text { Only } \\
(7)\end{array}$} & \multirow{2}{*}{$\begin{array}{c}\text { High Info } \\
\text { Only } \\
(8)\end{array}$} \\
\hline & (1) & (2) & & & $(5)$ & (6) & & \\
\hline Priority & $\begin{array}{c}0.288 * * * \\
(0.031)\end{array}$ & $\begin{array}{c}0.262 * * * \\
(0.041)\end{array}$ & $\begin{array}{c}0.262 * * * \\
(0.041)\end{array}$ & $\begin{array}{c}0.312 * * * \\
(0.045)\end{array}$ & $\begin{array}{c}0.291 * * * \\
(0.020)\end{array}$ & $\begin{array}{c}0.312 * * * \\
(0.024)\end{array}$ & $\begin{array}{c}0.310^{* * *} * \\
(0.025)\end{array}$ & $\begin{array}{c}0.271 * * * \\
(0.031)\end{array}$ \\
\hline Loophole & $\begin{array}{l}-0.061^{*} \\
(0.035)\end{array}$ & $\begin{array}{c}-0.024 \\
(0.047)\end{array}$ & $\begin{array}{c}-0.024 \\
(0.048)\end{array}$ & $\begin{array}{c}-0.106^{* *} \\
(0.048)\end{array}$ & $\begin{array}{c}-0.045^{* *} \\
(0.022)\end{array}$ & $\begin{array}{l}-0.017 \\
(0.028)\end{array}$ & $\begin{array}{l}-0.020 \\
(0.029)\end{array}$ & $\begin{array}{c}-0.077 * * \\
(0.033)\end{array}$ \\
\hline Info & & $\begin{array}{c}0.020 \\
(0.045)\end{array}$ & & & & $\begin{array}{c}0.020 \\
(0.035)\end{array}$ & & \\
\hline Info $*$ Priority & & $\begin{array}{c}0.050 \\
(0.061)\end{array}$ & & & & $\begin{array}{l}-0.043 \\
(0.040)\end{array}$ & & \\
\hline Info *Loophole & & $\begin{array}{c}-0.082 \\
(0.067)\end{array}$ & & & & $\begin{array}{l}-0.061 \\
(0.043)\end{array}$ & & \\
\hline Cost & $\begin{array}{c}-0.121 * * * \\
(0.007)\end{array}$ & $\begin{array}{c}-0.121^{* * *} \\
(0.007)\end{array}$ & $\begin{array}{c}-0.120^{* * *} \\
(0.010)\end{array}$ & $\begin{array}{c}-0.123 * * * \\
(0.010)\end{array}$ & $\begin{array}{c}-0.129 * * * \\
(0.006)\end{array}$ & $\begin{array}{c}-0.129 * * * \\
(0.006)\end{array}$ & $\begin{array}{c}-0.130 * * * \\
(0.008)\end{array}$ & $\begin{array}{c}-0.127 * * * \\
(0.009)\end{array}$ \\
\hline Round Dummies & Yes & Yes & Yes & Yes & Yes & Yes & Yes & Yes \\
\hline Observations & 9120 & 9120 & 4800 & 4320 & 18240 & 18240 & 9600 & 8640 \\
\hline Clusters & 76 & 76 & 40 & 36 & 76 & 76 & 40 & 36 \\
\hline R-squared & 0.23 & 0.24 & 0.21 & 0.27 & 0.25 & 0.25 & 0.26 & 0.26 \\
\hline
\end{tabular}


Since two subjects from each group are randomly chosen to have A-unit failure, the higher donation rate in the priority condition increases the number of B-units made available and average earnings. Across all rounds and both information conditions, average round earnings are $\$ 6.87$ under the priority rule as compared to $\$ 6.50$ in the control condition ( $\mathrm{p}<0.01$, robust standard errors clustered at the group level). But while the priority condition has a positive average effect on these variables, it favors the lowcost subjects (those who must pay $\$ 0.50$ to donate) over the high-cost subjects (those who must pay $\$ 4.00$ to donate). In the priority conditions, $85.5 \%$ of low-cost subjects donate and get priority while only $20.6 \%$ of high-cost subjects do so. Since many lowcost subjects have priority and few high-cost subjects do, high-cost subjects are significantly less likely to receive B units. Round earnings for the low-cost subjects rise from $\$ 6.54$ under control to $\$ 7.24$ under priority while earnings for the high-cost subjects fall from $\$ 6.40$ under control to $\$ 5.78$ under priority (for both tests $\mathrm{p}<0.01$, robust standard errors clustered at the group level).

What is the effect of adding a loophole to the priority allocation rule? Figure 2 shows that a loophole eliminates the increase in donation induced by priority. In Table 4, the Loophole coefficient has a negative sign for all specifications, indicating that donation rates in the loophole condition are at least directionally lower than in the control condition. In addition, the donation rates in the loophole condition are always statistically significantly lower than in the priority condition (tests of whether the coefficient on Priority is equal to the coefficient on Loophole are rejected with $\mathrm{p}<0.01$ for all regressions).

Why does the loophole lead to such a vast decrease in donation compared to the priority condition? First, the loophole completely undermines the incentive created by the priority rule. The only difference in incentives between the loophole condition and the control condition is that the loophole condition has a dominated option that allows a subject to be in a lower priority class (by choosing neither to donate nor take the loophole). If everyone donated or took the loophole, then all subjects would have priority and all subjects would have the same probability of receiving a B unit, an identical outcome to the control condition in which all subjects have the same probability of receiving a $\mathrm{B}$ unit. Outcomes in the loophole condition are quite close to this benchmark. 
Averaging across high and low cost subjects and high and low information conditions of the loophole treatment, we see that subjects only choose the dominated option $4 \%$ of the time. Put another way, across all rounds in the loophole condition, $96 \%$ of subjects have priority.

But while the incentives in the loophole condition are nearly the same as in the control condition, behavior is different. Donation rates are directionally, and sometimes significantly, lower in the loophole condition than in the control condition. The difference is statistically significant when pooling all the data in the experiment in regression (5) of Table 4: the coefficient on Loophole is negative and significant. Breaking down the data by information condition — as in regressions (3), (4), (7), and (8) of Table 4 - we see that this negative effect of the loophole is only directional for the low information condition but is statistically significant for the high information condition. Looking across all rounds in the high information condition in regression (8), subjects are 7.7 percentage points less likely to donate in the loophole condition than in the control condition, representing an $18.5 \%$ decrease in donation.

\section{Result 1: When informed about the actions of others, subjects are less likely to donate in the loophole condition than in the control condition}

It is worth noting two facts about Result 1. First, it is clear from the regressions (3), (4), (7), and (8), which analyze the information conditions separately, that the negative effect of the loophole is coming primarily from the high information condition. However, when comparing loophole to control, we do not get a significant interaction between the information conditions. As can be seen in regressions (2) and (6) of Table 4, Info *Loophole is not statistically significantly less than 0 (in regression (2), $\mathrm{p}=0.227$; in regression (6), $\mathrm{p}=0.160)$. One reason that we do not get a statistically significant interaction between information conditions is that even in the low information condition, the loophole generates directionally lower donation rates than in the control condition. As a consequence, when we combine all our data from both the low and high information conditions together, as in regression (5), we get a statistically significant negative coefficient on Loophole. 
Second, the negative effect of the loophole appears to be driven primarily by decisions in the first 15 rounds. The first 15 rounds provide a cleaner test of the effect of the loophole since donation rates in the latter 15 rounds may be influenced by decisions made in a different organ allocation condition during the first 15 rounds. (When we investigate the dynamics underlying the negative impact of the loophole, we will see some differences between the first and second half of the experiment.) Consequently, our primary test between the control and loophole condition is based on data from the first 15 rounds. Nevertheless, the negative effect of the loophole is not statistically significantly different in the latter 15 rounds from the first 15 rounds. In addition, the effect is still significant when including all 30 rounds together, and the added precision of our estimates from the extra data leads the p-values fall when we include all 30 rounds rather than just the first 15 .

Lower donation rates in the loophole condition than in the control condition indicate that subjects who would have donated in the absence of a priority allocation system choose not to donate when the system has a loophole. Why do these individuals choose not to donate in the presence of a loophole and why is the effect particularly strong in the high information condition?

To answer these questions, we investigate the dynamics underlying donation behavior. Table 5 reports regressions testing how the previous decisions of other subjects affects donation and whether this relationship varies between the loophole and control conditions. It reports results from the high information condition in regressions (1) through (4) and from the low information condition in regressions (5) through (8). All regressions have fixed effects to control for a subject's general proclivity to donate in an organ allocation condition. 
Table 5: Donation in the Control and Loophole Conditions

Others Not Donating

Others Not Donating t-1 $^{*}$ Loophole

Others Not Donating t-2 $*$ Loophole dummies Round*Loophole dummies

Fixed Effects (*Loophole if in both)

Observations

Clusters

R-squared

Donation ( 0 or 1$)$ in a Linear Probability Model (OLS)

\begin{tabular}{c|c|c|c|c|c|c|c}
\hline \multicolumn{4}{c|}{ High Information Only } & \multicolumn{4}{c}{ Low Information Only } \\
\hline \multicolumn{2}{c}{ First 15 Rounds } & \multicolumn{2}{c|}{ All 30 Rounds } & First 15 Rounds & \multicolumn{2}{c}{ All 30 Rounds } \\
\hline$(1)$ & $(2)$ & $(3)$ & $(4)$ & $(5)$ & $(6)$ & $(7)$ & $(8)$ \\
\hline-0.015 & -0.006 & -0.015 & -0.009 & -0.011 & -0.010 & -0.002 & -0.002 \\
$(0.012)$ & $(0.010)$ & $(0.010)$ & $(0.007)$ & $(0.009)$ & $(0.011)$ & $(0.007)$ & $(0.008)$ \\
-0.023 & $-0.034^{* *}$ & -0.020 & $-0.025^{* *}$ & $0.023^{*}$ & 0.020 & 0.010 & 0.012 \\
$(0.017)$ & $(0.015)$ & $(0.012)$ & $(0.012)$ & $(0.012)$ & $(0.014)$ & $(0.010)$ & $(0.011)$ \\
& & & & & & & \\
No & Yes & No & Yes & No & Yes & No & Yes \\
Yes & Yes & Yes & Yes & Yes & Yes & Yes & Yes \\
Yes & Yes & Yes & Yes & Yes & Yes & Yes & Yes \\
& & & & & & & \\
2688 & 2496 & 5152 & 4784 & 3136 & 2912 & 6048 & 5616 \\
24 & 24 & 36 & 36 & 28 & 28 & 40 & 40 \\
0.54 & 0.55 & 0.57 & 0.58 & 0.57 & 0.59 & 0.59 & 0.60 \\
\hline
\end{tabular}

Robust standard errors clustered by group are in parentheses: ${ }^{*}$ significant at $10 \%,{ }^{* *}$ significant at $5 \%,{ }^{*} *$ significant at $1 \%$. Others Not Donating $_{t-1}$ is the number of other subjects who did not donate (either chose not to donate or chose to take the loophole) in the previous round. Loophole is a dummy variable equal to 1 if the data is from the loophole condition and interactions with Loophole test for differences between the loophole and control conditions. Others Not Donating ${ }_{t-2}{ }^{*}$ Loophole dummies indicate a dummy variable for each number of non-donors two periods ago, which might be different for the loophole and control conditions. Round*Loophole dummies include a dummy for each round of the game, which might be different for loophole and control conditions. Fixed Effects (*Loophole if in both) includes a dummy for each subject in each condition (i.e. for subjects who played in both the control and loophole conditions, we allow them to have a different fixed effect in each treatment, which is only relevant for a subset of subjects in the All 30 Rounds regressions). All regressions exclude round 1 (and round 16 if analyzing All 30 Rounds). When we control for Others Not Donating $t_{-2}$, we also exclude rounds 2 (and 17). 
Table 5 shows that in the high information condition, subjects are more responsive in the loophole condition than in the control condition to previous round actions of other. The coefficeint Others Not Donating $t_{t-1}$ reports the effect on donation of the number of free riders in the previous round (i.e. subjects who chose not to donate in the control condition and who chose not to donate or chose to take the loophole in the loophole condition). In regressions (1) through (4), Others Not Donating ${ }_{t-1}$ is directionally negative, suggesting that subjects in the control condition are somewhat less likely to donate when more of their group members failed to donate in the previous round. In

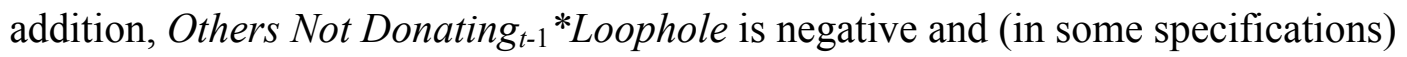
significant, demonstrating that subjects are more responsive to free riding in the loophole condition than in the control condition.

As expected, we see no such pattern in the low information condition in which subjects do not actually observe the choices of others (instead they get a noisy signal of others' choices by either receiving or not receiving a B unit when they need one). For the loophole condition, subjects' responsiveness to the previous round actions of others is the sum of Others Not Donating t-1 $_{1}$ and Others Not Donating ${ }_{t-1}$ *Loophole. This is always significantly different from 0 in the high information regressions $(\mathrm{p}<0.01$ for all tests) and never statistically different from 0 in the low information regressions $(\mathrm{p}>0.1$ for all tests).

\section{Result 2: When informed, subjects in the loophole condition respond more than subjects in the control condition to the number of free riders in the previous round}

Why are subjects in the loophole condition more responsive to free riding? Since almost all subjects who free ride in the loophole condition do so by taking the loophole, it may be that subjects respond more negatively to others who take the loophole rather than who do not donate but do not take priority.

Table 6 conducts this analysis by looking exclusively at the loophole condition and controlling for the number of other subjects who donated in the previous round. In regression (1) of Table 6, the coefficient Others took loophole li- $_{1}$ is negative and significant, indicating that in the first 15 rounds of the game subjects are 6.8 percentage 
points less likely to donate for each additional person who took the loophole rather than simply did not donate without taking priority.

Table 6: Donation in the Loophole Condition

Donation (0 or 1$)$ in a Linear

Probability Model (OLS)

\begin{tabular}{|c|c|c|c|}
\hline \multirow[b]{3}{*}{ Others Took Loophole Lo $_{t-1}$} & \multirow{2}{*}{$\frac{\text { All Data }}{\text { (1) }}$} & \multirow{2}{*}{$\frac{\operatorname{Cos} t=\$ 0.50}{(2)}$} & \multirow{2}{*}{$\frac{\text { Cost }=\$ 4.00}{(3)}$} \\
\hline & & & \\
\hline & $\begin{array}{c}-0.068 * * * \\
(0.023)\end{array}$ & $\begin{array}{c}-0.071 * * \\
(0.025)\end{array}$ & $\begin{array}{l}-0.051 \\
(0.055)\end{array}$ \\
\hline Others Took Loophole LI $^{*}$ Late & $\begin{array}{l}0.076^{*} \\
(0.037)\end{array}$ & $\begin{array}{l}0.082 * \\
(0.045)\end{array}$ & $\begin{array}{c}0.044 \\
(0.063)\end{array}$ \\
\hline Others Donated $\mathrm{t}_{\mathrm{t}-1}{ }^{*}$ Late dummies & Yes & Yes & Yes \\
\hline Round dummies & Yes & Yes & Yes \\
\hline Fixed Effects & Yes & Yes & Yes \\
\hline Observations & 2240 & 1680 & 560 \\
\hline Subjects & 160 & 120 & 40 \\
\hline Clusters & 20 & 20 & 20 \\
\hline R-squared & 0.51 & 0.49 & 0.42 \\
\hline \multicolumn{4}{|c|}{$\begin{array}{l}\text { Robust standard errors clustered by group are in parentheses: } * \text { significant at } 10 \% \text {, } \\
* * \text { significant at } 5 \%, * * * \text { significant at } 1 \% \text {. Others Took Loophole }{ }_{t-1} \text { is the } \\
\text { number of other subjects who took the loophole in the previous round. Late is a } \\
\text { dummy variable equal to } 1 \text { if the data is from the second half of the experiment, } \\
\text { after subjects had already participated in one other organ allocation condition and } \\
\text { interactions with Late test for differences between the first and second half of the } \\
\text { experiment. Others Donated }{ }_{t-1}{ }^{*} \text { Late dummies indicate a dummy variable for each } \\
\text { number of other donors who contributed in the previous round, a dummy variable } \\
\text { that might be different in the first and second half of the experiment. Therefore, } \\
\text { these dummies absorb the direct effect of Others Donated } \text { Def }_{t-1} \text { and are allowed to } \\
\text { differ in the first and second half of the experiment. Round dummies include a } \\
\text { dummy for each round of the game. All regressions exclude round } 1 \text { and round } 16 \\
\text { for which there is no previous round behavior to observe. }\end{array}$} \\
\hline
\end{tabular}

Results from Table 6 also help to explain why the negative effect of the loophole is particularly strong in the first 15 rounds of the game. After subjects have had experience playing the game in another condition, they appear to become less sensitive to the effect of individuals taking the loohole in the previous round. In regressions (1) and

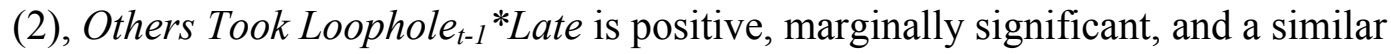
magnitude as Others Took Loophole ${ }_{t-1}$, indicating that there is no effect of more subjects taking the loophole in the second half of the experiment. 


\section{Result 3: In the first half of the experiment, subjects are less likely to donate when they see non-donors take the loophole rather than stay in the lower priority class}

The negative effect on donation associated with others taking the loophole in the previous round is driven primarily by the six members of each group who have low cost of donation (i.e. \$0.50) as reported in regression (2). However we see the same pattern just more muted - on subjects with a high cost of donation in regression (3). This is sensible given that the low-cost subjects are more likely to contribute than the high-cost subjects, and so for low-cost subjects we are more likely to observe a significant response in donation to the actions of others.

\section{Discussion}

In our experiment, the introduction of a priority rule significantly increased the number of subjects who paid the cost to donate their B units. Adding a loophole to the priority rule, as is allowed in the implementation of the Israeli priority system, completely undermined the beneficial effect of priority. In addition, when information about donation and the use of the loophole was made public, the loophole condition led to even less donation than the control condition.

That the priority rule increases donation rates shows that we replicate results from Kessler and Roth (2012) with a different experimental set-up and parameters. In the control condition, the primary incentive to donate came from the fact that donating generated \$2.00 in expected earnings for other subjects. ${ }^{16}$ Under a priority allocation rule, there is an additional incentive to donate in that subjects are more likely to receive a $\mathrm{B}$ unit worth $\$ 4.00$ if they donate. In fact, given the monetary payoffs in the game, there is an equilibrium in which all low-cost subjects donate in a given round of the priority condition. (Assuming all other low-cost subjects donate, the expected benefit of having priority is $\$ 1.52$, which is well above the $\$ 0.50$ cost of donation faced by low-cost

\footnotetext{
${ }^{16}$ Since the game is played repeatedly with the same group, there may be strategic reasons to donate in a given round if it leads others to contribute in later rounds.
} 
subjects. $)^{17}$ Of course, there is always an equilibrium in which no one donates, since priority has no value to a single donor - he can never give a B unit to himself.

As expected, the priority allocation rule increases the number of donors, which is accompanied by more B units being made available and higher earnings overall. In doing so, however, the priority rule harms high-cost subjects - who rarely donate and so are less likely to receive a B unit in the priority condition than in the control condition while substantially improving outcomes for the low-cost subjects.

One might think such inequality created by the policy is fair, for example since individuals with high costs of donation are much less likely to provide the public good by donating their B units, so it might make sense that they benefit less from the public good (see Lavee and Brock 2012). Alternatively, one might think that the inequality created by the policy is unfair or even unethical, for example if costs are a function of religious beliefs on the basis of which we do not want to discriminate.

A policy maker who wants to mitigate the inequality created by a priority rule might imagine giving high-cost donors a way of receiving priority without paying their substantial costs of donation, for example with a loophole that allows high-cost donors to receive priority without donating. The check box on the Israeli organ donor card, which asks for a clergyman to be consulted before donation, may aim to serve the purpose of providing a loophole for individuals whose religious beliefs make organ donation particularly costly. However, if policy makers cannot perfectly infer the costs of donation (or if they are restricted from using a proxy like religion), loopholes may be available to

\footnotetext{
${ }^{17}$ The calculation of the value of priority and the existence of the equilibrium is outlined here. To show this equilibrium exists, we assume that all other low-cost subjects donate and that neither of the high-cost subjects donate, and we ask whether the last low-cost subject wants to donate. With probability 0.25 , that subject has A-unit failure and gets no benefit from priority. Conditional on having B-unit failure, there are three possible outcomes: (1) both A-unit failures are high-cost players, which occurs with probability $\left(2 / 7^{*} 1 / 6\right)=2 / 42$, and generates no value from priority; (2) one A-unit failure is a low-cost subject, which occurs with probability $(2 * 2 / 7 * 5 / 6)=20 / 42$, and generates a value from priority of $\$ 4 *(2 / 5-0)=\$ 1.60$, since having priority puts the subject in the pool for $2 \mathrm{~B}$ units with the 4 other low-cost donors with B-unit failure; (3) both A-unit failures are low-cost donors, which occurs with probability $(5 / 7 * 4 / 6)=20 / 42$, and generates value from priority of $\$ 4 *(1-1 / 3)=\$ 2.67$, since having priority secures one of the four B units for sure rather than having a $1 / 3$ chance of getting the last $B$ unit in the non-priority pool. The total expected benefit to priority is $0.75 *(2 / 42 * \$ 0+20 / 42 * \$ 1.60+20 / 42 * \$ 2.67)=\$ 1.52$. Notice that the high-cost players never donate in equilibrium, since their cost of donation is $\$ 4.00$, while the benefit of getting a B unit is $\$ 4.00$ and so the expected benefit of having priority is always less than $\$ 4.00$.
} 
everyone. While the box on the Israeli donor card may have been intended to satisfy religious groups, anyone can check it.

What is the consequence of introducing a loophole option into the priority allocation rule? We find that if it a loophole is available, both those with low costs of donation and high costs of donation take advantage of the loophole - only $4 \%$ of actions in the loophole condition were subjects who chose neither to donate nor take the loophole. The ubiquitous use of the loophole among non-donors completely eliminated the gain from priority. In addition, when the loophole was available and individuals were provided with information about its use, donation levels were lower than in the control condition that did not have a priority system.

In interpreting this experimental result, one might be concerned that the high information condition - in which subjects are informed of the number of individuals in each round who donated, the number who did not donate, and the number who took loophole — induces an experimenter demand effect. We have two responses to this concern. First, it does not seem obvious whether reporting the use of the loophole would be interpreted as the experimenter encouraging or discouraging its use. Second, if demand effect concerns are that by explicitly reporting use of the loophole we are discouraging potential donors from contributing (and doing so in a heavy handed way), we think this speaks exactly to one of the lessons of the paper. Namely, policy makers might want to suppress information about the use of the loophole to avoid equivalent demand effects in the real world. ${ }^{18}$

Results from the high information condition suggest that one reason for this decrease in donation is that subjects withhold donation when they see others take advantage of the loophole. This response to the number of group members who take the loophole comes in part from a standard conditional cooperation motive (see, e.g. Fischbacher, Gachter and Fehr 2001) in which subjects are more likely to contribute to

\footnotetext{
${ }^{18}$ In the case of Israel, the ultraorthodox religious groups that generally do not recognize brain death and consequently oppose providing deceased donor organs are very active living donors of kidneys. Policy makers might choose to report total living and deceased organ donation together rather than just deceased donation numbers, which reported alone might suggest loophole use.
} 
public goods when others contribute. ${ }^{19}$ However, the use of a loophole in a priority organ allocation system is a special case in which subjects both free ride by not contributing and abuse a system designed to benefit contributors and punish free riders. We see that even controlling for the number of subjects who donated in the previous round, subjects are less likely to donate when they observe non-donors take the loophole rather than stay in the lower priority class (at least in the first 15 rounds of the experiment).

To take advantage of the loophole in the Israeli system requires an individual to sign a donor card to receive priority with the specific intention of having that donation revoked if ever in a position to donate. There are additional psychological costs that may arise by taking advantage of a loophole in this way, for example individuals may feel like they have made a promise (see Gneezy 2005; Charness and Dufwenberg 2006, 2010; Vanberg 2008) or agreed to a contract (see Kessler and Leider 2012) that they feel obligated to fulfill. ${ }^{20}$ By providing the loophole as a simple third option along with options to donate and not donate, we likely minimized these costs, although the $4 \%$ of actions in the loophole condition in which subjects neither donated nor took the loophole suggests at least some (minimal) reluctance to taking the loophole. ${ }^{21}$

While this paper investigates priority allocation systems and how loopholes can undermine them, there are a number of other strategies that might be employed to increase the number of individuals who register as organ donors or donate an organ while alive. One approach is to change the way individuals are asked to register. Some have advocated a switch from an opt-in protocol, in which individuals check a box to register and leave it blank not to register, to a "mandated choice" or "active choice" protocol, in which individuals must choose between joining the registry or not joining the registry

\footnotetext{
${ }^{19}$ The argument in Lavee et al. (2010) suggests that organ donation rates in Israel have been historically low because of the presence of free riders, which also highlights a conditional cooperation motive. Notice that in our study there are also free riders in the control condition but donations fall further when a loophole is available.

${ }^{20}$ If these costs are larger than the benefit of being in the priority class, individuals may choose to forgo the loophole and simply not donate.

${ }^{21}$ Twenty percent of subjects who played in the loophole condition chose not to donate and not to take the loophole in at least one round. That said, among this $20 \%$, the choice was selected on average only 3 times out of the 15 rounds. Only one subject out of 368 who played in the loophole condition chose not to donate and not to take the loophole in all 15 rounds.
} 
(see Thaler and Sunstein 2008, Thaler 2009). ${ }^{22}$ Another approach is to facilitate kidney exchange, in which incompatible patient-donor pairs are matched. This process finds compatible patient-donor pairs where donor A gives a kidney to donor B's patient while donor B gives a kidney to donor A's patient (Roth, Sonmez and Unver 2004, 2005a,b, 2007; Roth et al. 2006; Saidman et al. 2006). ${ }^{\mathbf{2 3}}$

Results from our paper demonstrate that along with these other strategies, organ allocation policy may be a powerful tool to increase the number of deceased donor organs that are made available for transplantation, for example by providing priority on organ waiting lists for registered donors. But how such allocation rules are implemented can make a significant difference on their efficacy. Allowing loopholes in which individuals can receive priority without ever being in a position to donate can undermine the benefits of the priority system and could actually be worse than forgoing the priority allocation system all together.

While this paper has focused on the decision to register as an organ donor, we believe our results speak more broadly to other contexts. The pool of registered organ donors is like a common property resource since registering increases the pool of potential donors in expectation and thus benefits the entire pool of potential recipients. The priority rule we study here introduces excludability by giving preferential access to the resource to people who contribute. We find that allowing a loophole gives noncontributors equal access, undermines the incentive effects of the priority system ${ }^{24}$ and leads potential donors to withhold contribution. This latter result arises when subjects

\footnotetext{
${ }^{22}$ This policy change has been implemented in Great Britain as well as a number of U.S. states, including Illinois and California (New York State just passed similar legislation). Recent research, however, suggests that changing the way individuals are asked to register can have a perverse effect on total donations, particularly from the next of kin of unregistered donors. In particular, individuals seem to treat the desire not to join the registry under mandated choice as more sacrosanct than failing to opt-in to the registry (Kessler and Roth 2013).

${ }^{23} \mathrm{New}$ institutions have been formed to organize these exchanges and to create chains of donation that start with a single undirected donor (see Roth et al. 2006 and Ashlagi et al. 2011). As a consequence there have been over 2000 transplants due to kidney exchange since 2004 according to data reported to the Organ Procurement and Transplantation Network (see http://optn.transplant.hrsa.gov/latestData/rptData.asp).

${ }^{24}$ This result bears similarities to risk pooling systems with moral hazard (see, e.g. Fafchamps and Lund 2003) but with different timing and a one-shot structure where people can either contribute to the system or take from it. A priority rule helps to enforce risk pooling by forcing individuals who want the insurance of receiving an organ if they need one to commit to sharing their organs if they die first. The loophole introduces moral hazard into the system.
} 
observe others take the loophole, suggesting that if a loophole cannot be avoided, then it may be prudent to avoid broadcasting its use. Planners that run club goods and excludible common property resources (e.g. membership-funded swimming pools, golf courses, parks, cultural institutions, and religious organizations) may want to avoid the creation of loopholes that allow access without membership. At the very least, they may not want to highlight when non-members take advantage of a loophole to use the facilities rather than paying their dues. 


\section{References}

Andreoni, James. "Privately provided public goods in a large economy: The limits of altruism." Journal of Public Economics, 1988, 35(1), pp. 57-73.

Andreoni, James. "Giving with Impure Altruism: Applications to Charity and Ricardian Equivalence.” Journal of Political Economy, 1989, 97(6), pp. 1447-1458.

Andreoni, James. "Impure altruism and donations to public goods: A theory of warmglow giving." The Economic Journal, 1990, 100(401), pp. 464-477.

Ariely, Dan, Anat Bracha and Stephan Meier. "Doing good or doing well? Image motivation and monetary incentives in behaving prosocially." American Economic Review, 2009, 99(1), pp. 544-555.

Becker, Gary S. “A Theory of Social Interactions.” Journal of Political Economy, 1974, 82(6), pp. 1063-1093.

Benabou, Roland and Jean Tirole. "Incentives and Prosocial Behavior." American Economic Review, 2006, 96(5), pp. 1652-1678.

Charness, Gary, Martin Dufwenberg. "Promises and partnerships." Econometrica, 2006, 74(6), pp. 1579-1601.

Charness, Gary, Martin Dufwenberg. "Bare promises: An experiment." Economic Letters, 2010, 107(7), pp. 281-283.

Deci, E. L., R. Koestner, R. M. Ryan. "A meta-analytic review of experiments examining the effects of extrinsic rewards on intrinsic motivation." Psychology Bulletin, 1999, 125(6), pp. 627-668.

Donate Life America. National Donor Designation Report Card 2012. Richmond, VA: Donate Life America, 2012.

Fafchamps, Marcel and Susan Lund. "Risk-sharing networks in rural Philippines." Journal of Development Economics, 2003, 71(2), pp. 261-287.

Fischbacher, Urs. "z-Tree: Zurich Toolbox for Ready-made Economic Experiments." Experimental Economics, 2007, 10, pp. 171-178.

Fischbacher, Urs, Simon Gachter and Ernst Fehr. "Are People Conditionally Cooperative? Evidence from a Public Goods Experiment.” Economics Letters, 2001, 71(3), pp. 397-404. 
Frey, Bruno S. and Stephan Meier. "Social Comparisons and Pro-Social Behavior:

Testing 'Conditional Cooperation' in a Field Experiment." The American Economic Review, 2004, 94(5), pp. 1717-1722.

Glazier, Alexandra K. "Donor Rights and Registries." Journal of Medical Ethics, 2006, 13(1), pp. 4.

Gneezy, Uri. "Deception: The role of consequences." The American Economic Review, 2005, 95(1), pp. 384-394.

Gneezy, Uri, Aldo Rustichini. "Pay enough or don't pay at all." Quarterly Journal of Economics, 2000a, 115(3), pp. 791-810.

Gneezy, Uri, Aldo Rustichini. “A fine is a price.” Journal of Legal Studies, 2000b, 29(1), pp. 1-18.

Keser, Claudia and Frans van Winden. "Conditional Cooperation and Voluntary Contributions to Public Goods." Scandinavian Journal of Economics, 2000, 102(1), pp. 23-39.

Kessler, Judd B., and Stephen Leider. "Norms and Contracting." Management Science, 2012, 58(1), pp. 62-77.

Kessler, Judd B., and Alvin E. Roth. "Organ Allocation Policy and the Decision to Donate." American Economic Review, 2012, 102(5), pp. 2018-47.

Kessler, Judd B., and Alvin E. Roth. "Don't Take 'No' For an Answer: An experiment with actual organ donor registrations." 2013, working paper.

Lacetera, Nicola, and Mario Macis. "Social Image Concerns and Prosocial Behavior: Field Evidence from a Nonlinear Incentive Scheme." Journal of Economic Behavior and Organization, 2010a, 76(2), pp. 225-37.

Lacetera, Nicola, and Mario Macis. "Do all material incentives for prosocial activities backfire? The response to cash and non-cash incentives for blood donations." Journal of Economic Psychology, 2010b, 31(4), pp. 738-748.

Lacetera, Nicola, Mario Macis, and Robert Slonim. "Will There Be Blood? Incentives and Displacement Effects in Pro-Social Behavior." American Economic Journal: Economic Policy, 2012, 4(1), pp. 186-223.

Lavee, Jacob, Tamar Ashkenazi, Avi Stoler, J. Cohen, and R. Beyar. "Preliminary Marked Increase in the National Organ Donation Rate in Israel Following Implementation of a New Organ Transplantation Law." American Journal of Transplantation, 2013, 13, pp. 780-785. 
Lavee, Jacob, Tamar Ashkenazi, Gabriel Gurman, and David Steinberg. "A new law for allocation of donor organs in Israel.” Lancet, 2010, 375, pp. 1131-1133.

Lavee, Jacob and Dan W. Brock. "Prioritizing registered donors in organ allocation: an ethical appraisal of the Israeli organ transplant law." Current Opinion in Critical Care, 2012, 18(6), pp. 207-211.

Mellstrom, Carl, and Magnus Johannesson. "Crowding Out in Blood Donation: Was Titmuss Right?” Journal of the European Economic Association, 2008, 6(4), pp. 845-63.

Potters, Jan, Martin Sefton and Lise Vesterlund. "After you - endogenous sequencing in voluntary contribution games." Journal of Public Economics, 2005, 89, pp. 1399-1419.

Roth, Alvin E., Tayfun Sönmez, and M. Utku Ünver. "Kidney Exchange.” Quarterly Journal of Economics, 2004, 119(2), pp. 457-88.

Roth, Alvin E., Tayfun Sönmez, and M. Utku Ünver. "A Kidney Exchange Clearinghouse in New England.” American Economic Review, 2005a, 95(2), pp. 376-80.

Roth, Alvin E., Tayfun Sönmez, and M. Utku Ünver. "Pairwise Kidney Exchange." Journal of Economic Theory, 2005b, 125(2), pp. 151-88.

Roth, Alvin E., Tayfun Sönmez, and M. Utku Ünver. "Efficient Kidney Exchange: Coincidence of Wants in Markets with Compatibility-Based Preferences." American Economic Review, 2007, 97(3), pp. 828-51.

Roth, Alvin E., Tayfun Sönmez, M. Utku Ünver, Francis L. Delmonico, and Susan L. Saidman. "Utilizing List Exchange and Undirected Good Samaritan Donation through 'Chain' Paired Kidney Exchanges." American Journal of Transplantation, 2006, 6(11), pp. 2694-2705.

Roth, Alvin E. "Repugnance as a Constraint on Markets." Journal of Economic Perspectives, 2007, 21(3), pp. 37-58

Saidman, Susan L., Alvin E. Roth, Tayfun Sönmez, M. Utku Ünver, and Francis L. Delmonico. "Increasing the Opportunity of Live Kidney Donation By Matching for Twoand Three-Way Exchanges.” Transplantation, 2006, 81(5), pp. 773-82.

Shang, Jen and Rachel Croson. "A Field Experiment In Charitable Contribution: The Impact of Social Information on the voluntary provision of public goods." The Economic Journal, 2009, 119, pp. 1422-1439.

Thaler, Richard H. and Cass R. Sunstein. Nudge: Improving Decisions about Health, Wealth, and Happiness. New Haven, CT: Yale University Press, 2008. 
Thaler, Richard H. "Opting in versus Opting out." The New York Times, September 26, 2009.

Titmuss, Richard M. The Gift Relationship, Allen and Unwin, 1970.

U.S. Department of Health and Human Services, Health Resources and Services Administration, Healthcare Systems Bureau, Division of Transplantation, 2008 Annual Report of the U.S. Organ Procurement and Transplantation Network and the Scientific Registry of Transplant Recipients: Transplant Data 1998-2007, Rockville, MD.

U.S. Department of Health and Human Services, Health Resources and Services Administration, Healthcare Systems Bureau, Division of Transplantation, 2009 Annual Report of the U.S. Organ Procurement and Transplantation Network and the Scientific Registry of Transplant Recipients: Transplant Data 1999-2008, Rockville, MD.

U.S. Department of Health and Human Services, Health Resources and Services Administration, Healthcare Systems Bureau, Division of Transplantation, 2011 Annual Report of the U.S. Organ Procurement and Transplantation Network and the Scientific Registry of Transplant Recipients: Transplant Data 2001-2010, Rockville, MD.

Vanberg, Christoph. "Why do people keep their promises? An experimental test of two explanations.” Econometrica, 2008, 76(6), pp. 1467-1480.

Articles cited:

http://www.haaretz.com/print-edition/news/officials-new-donor-cards-will-reduce-organtransplants-1.374566

Data sources:

http://optn.transplant.hrsa.gov/latestData/rptData.asp 